\title{
Identidad profesional docente ${ }^{11}$
}

\section{Dr. Luis Ángel Prieto Carnicero²}

En la actualidad, por la infinita variedad de actividades a realizar, la condición de profesor debería estar incluida entre las "profesiones de riesgo": ha de ser un profesional que motive; innovador en sus métodos; hacer que sus alumnos superen con éxito las distintas evaluaciones — no solo del centro, sino internacionales, y ellos mismos estarán sujetos a evaluación-; atender a la diversidad; integrar las nuevas tecnologías en su práctica

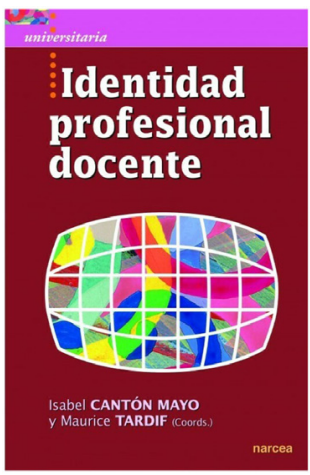
docente; afrontar los cambios legislativos en los programas de estudio; cooperar y coordinarse con otros profesores; colaborar con los padres y otros agentes escolares...

Sumado a lo anterior, hay que tener en cuenta la evolución de su rol. Si bien el profesor era la figura encargada de guiar a sus alumnos en el aprendizaje y desarrollo necesarios para que éstos alcanzaran la plenitud personal, ahora sus distintas identidades se solapan, pudiendo actuar de educador, tutor, padre, vigilante, psicólogo, trabajador social, administrativo, coordinador de equipo, miembro del consejo escolar, responsable de nivel... Con tales antecedentes, el profesor ha pasado de ser un profesional por vocación a un burócrata por obligación.

Además, la educación ha ido perdiendo su sesgo humanista, encargada de la formación y transmisión no solo del conocimiento, sino de valores humanos, para ser interpretada como un capital, que sirva para incrementar el crecimiento económico. Es la nueva economía del saber.

Reseña. Corresponde a la revisión del libro: Cantón, I. y Tardif, M. (Coords.) (2018). Identidad profesional docente. Madrid, España: Narcea - Universitaria. 229 páginas. ISBN: 978-84-277-2396-2. Doctor en Psicología y Ciencias de La Educación y Licenciado en Lingüistica, Universidad de León (España).Contacto: theroyalbritishempire@gmail.com 
Como se puede observar, son muchas y variadas las dimensiones que el docente se va encontrando durante su etapa de educador, necesarias para construir, de cara a sí mismo y hacia los demás, su propia identidad laboral. Así, para ayudar a cimentar el tortuoso camino de la Identidad profesional docente, surge este libro con dicho título, coordinado por Isabel Cantón Mayo y Maurice Tardif, quienes, a su vez, también son autores de sendos capítulos.

Con esta obra se persiguen tres objetivos: revisar las distintas aportaciones a la construcción de la identidad profesional docente; actualizar y completar el conocimiento sobre el tema, y presentar una perspectiva comparativa multidisciplinar e internacional.

El texto recoge los diferentes puntos de vista que los autores tienen sobre el proceso de construcción de la identidad profesional de los docentes. E, incluso, se incluye algún enfoque sobre el proceso contrario, de destrucción de tal identidad.

Se recorre el proceso desde un planteamiento del profesor como individuo. Igualmente, como miembro de una institución académica, justificando así el estudio que se expone en algunos capítulos que inciden sobre las distintas identidades docentes, según se correspondan con el nivel de Educación Primaria, Secundaria o Superior.

En ocasiones, se complementa con una perspectiva internacional, en la que países como Canadá, Suiza o Francia, por ejemplo, sirven como plataforma para fundamentar el estudio. El aporte de tales experiencias permite la observación de la singularidad de cada contexto internacional, en ocasiones extrapolables a paralelismos referidos al mismo asunto en cualquier otro país.

A lo largo del libro, constituido por una introducción y doce capítulos, se aborda el concepto de identidad docente desde un enfoque pluridimensional:

- Desde un ámbito formalmente sociológico.

- Desde el análisis de la calidad de la identidad de los docentes y fundamentado en diversos estudios interesados en la satisfacción 
profesional de los mismos, e indagando sobre aquellos indicadores que más se relacionan entre calidad y satisfacción.

- Desde la reflexión, mediante el estudio del babitus, esquemas que organizan la conducta de un individuo en situaciones que se va encontrando. Son soluciones que el educador tendrá que proponer a problemas que van surgiendo en su etapa docente. Se analiza la transformación de tales esquemas desde una identidad de estudiante a la de un docente principiante, proceso en el que el saber académico evoluciona hacia un saber profesional.

- Desde una labor colectiva del profesorado, siendo el centro educativo el eje vertebrador de los procesos de actuación e interacción, de forma presencial o virtual, mediante el trabajo colaborativo, a través de las Comunidades de Práctica Profesional, como grupos profesionales de reflexión, creación y gestión del conocimiento, cuyos resultados revierten en la mejora de la institución, de la sociedad y, por supuesto, de la identidad profesional del docente.

- Desde una visión sanitaria, en la que se presentan las enfermedades más comunes que los docentes no universitarios sufren en su práctica profesional, así como la aportación de las líneas de actuación necesarias para afrontar su prevención.

- Desde un aspecto político. A través de una retrospectiva histórica, comprendida entre los siglos XIX al XXI, se examina el contenido de planes de estudio que han servido como instrumentos para cimentar, durante la formación, la base de la profesión docente, encarnada en aquellos conocimientos, normas, valores y medios necesarios en el proceso de construcción de la identidad profesional docente.

No hay que olvidar que la consecución de la identidad docente es un proceso dialéctico en permanente construcción, inacabado. Por tal motivo, la lectura de la obra es recomendable tanto para aquellos profesores que se encuentran en los inicios de su profesión, como para aquellos otros que posean una dilatada experiencia; sin excluir a los estudiantes, futuros docentes, o cuantos mantengan algún vínculo con la educación. Entendemos que existe una relación indisociable entre los tres tipos de identidad de las que habla Zabalza en su capítulo, 
RESEÑAS

esto es, la personal, la profesional y la organizativa o institucional, y conjugar con éxito esa tríada, en una realidad tan cambiante, puede ser una difícil tarea si los docentes no encuentran las herramientas necesarias para superar y adaptarse a los cambios sobrevenidos, mostrándose incapaces de redefinir su trabajo docente. Por ello, debido al carácter multidisciplinar de este libro, considérese oportuna su lectura como una de esas herramientas necesarias, que servirá para aportar algo más de luz en el panorama conceptual de la identidad profesional docente. 